Portland State University

PDXScholar

Environmental Science and Management

Faculty Publications and Presentations

7-2017

\title{
Ecological Homogenization of Residential Macrosystems
}

\author{
Peter M. Groffman \\ University of New York \\ Meghan Avolio \\ National Socio-Environmental Synthesis Center \\ Jeannine Cavender-Bares \\ University of Minnesota - St. Paul \\ Neil D. Bettez \\ Cary Institute of Ecosystem Studies \\ J. Morgan Grove \\ U.S. Forest Service
}

See next page for additional authors

Follow this and additional works at: https://pdxscholar.library.pdx.edu/esm_fac

Part of the Environmental Sciences Commons

Let us know how access to this document benefits you.

\section{Citation Details}

Groffman, P. M., Avolio, M., Cavender-Bares, J., Bettez, N. D., Grove, J. M., Hall, S. J., ... \& Heffernan, J. B. (2017). Ecological homogenization of residential macrosystems. Nature Ecology and Evolution, 1(7).

This Article is brought to you for free and open access. It has been accepted for inclusion in Environmental Science and Management Faculty Publications and Presentations by an authorized administrator of PDXScholar. Please contact us if we can make this document more accessible: pdxscholar@pdx.edu. 


\section{Authors}

Peter M. Groffman, Meghan Avolio, Jeannine Cavender-Bares, Neil D. Bettez, J. Morgan Grove, Sharon J. Hall, Sarah E. Hobbie, Kelli L. Larson, Susannah B. Lerman, Dexter H. Locke, James B. Heffernan, Jennifer L. Morse, Christopher Neill, Kristen C. Nelson, Jarlath O'Neil-Dunne, Diane E. Pataki, Colin Polsky, Rinku Roy Chowdhury, and Tara Trammell 


\title{
Ecological homogenization of residential macrosystems
}

\author{
Peter M. Groffman, Meghan Avolio, Jeannine Cavender-Bares, Neil D. Bettez, J. Morgan Grove, \\ Sharon J. Hall, Sarah E. Hobbie, Kelli L. Larson, Susannah B. Lerman, Dexter H. Locke, James B. Heffernan, \\ Jennifer L. Morse, Christopher Neill, Kristen C. Nelson, Jarlath O'Neil-Dunne, Diane E. Pataki, \\ Colin Polsky, Rinku Roy Chowdhury and Tara L. E. Trammell
}

\section{Similarities in planning, development and culture within urban areas may lead to the convergence of ecological processes on continental scales. Transdisciplinary, multi-scale research is now needed to understand and predict the impact of human-dominated landscapes on ecosystem structure and function.}

U rban, suburban and exurban land uses cover an increasingly large area of the United States ${ }^{1}$, and the consequences of human residential landscapes have received heightened attention in ecology and evolution over the past 30 years. This emergence has been driven by the recognition that human populations are increasingly concentrated in cities, where human activities and social processes, high impervious cover that creates novel climate and hydrology, and highly fragmented habitats all interact to uniquely alter ecological and evolutionary processes ${ }^{2,3}$.

In recent years, the spatial scope of urban ecology has expanded, driven by ideas about urban 'homogenization' or 'convergence,' wherein cities with very different climates and histories have been hypothesized to have similar mixes of trees, shrubs, grasslands and impervious surfaces that lead to similar ecosystem structure, function and services ${ }^{4,5}$. The focus on homogenization has coincided with the emergence of interest in 'macrosystems' biology, defined ${ }^{6}$ as "regional to continental extents with distances spanning hundreds to thousands of kilometres with biological, geophysical and social components that interact with one another and with phenomena at other spatial or temporal scales ranging from days to millennia." In North America, in an analysis focused on single-family residential parcels, we have characterized a large, ecologically homogenous 'American residential macrosystem' that has continental-scale impacts on water, energy, carbon and nutrient dynamics, despite some variation in social priorities ${ }^{7}$ and practices ${ }^{8}$ at different scales. In this comment, we describe these effects and address current research gaps. Specifically, will the homogenous American residential macrosystem persist in the next century or is it dynamic? How will alternative approaches to managing these systems influence the ecological system? And what are the social benefits and dis-amentities of these alternative futures? We make the case that the large and expanding extent of this system at the interface with agricultural and less human-dominated systems will have broader, continental-scale impacts on community assembly, evolution and ecosystem response to global environmental change over the next $50-100$ years. We predict that societal desires for biodiversity, water conservation, reduced delivery of pollutants to receiving waters and aesthetic ecological amenities will lead to marked changes in residential macrosystems across the globe and a reduction in ecological homogenization. Alternatively, factors such as a desire for neatness, low maintenance, neighbourhood norms and covenants, and real estate markets that function as agents of stability may overcome these factors driving change. We also predict that the increases in biodiversity caused by residential land management will increase the dynamism of natural ecosystems in and around residential macrosystems as new species alter the nature and extent of ecosystem response to global environmental change.
Urbanization and carbon sequestration In ongoing research funded by the US National Science Foundation (NSF) Macrosystems Biology programme, we have characterized and evaluated continental- scale effects of urban homogenization on plant biodiversity, soil carbon and nitrogen pools and processes, microclimate, hydrography and land cover in residential

land-use in six cities across the US (Boston, Baltimore, Miami, Minneapolis-Saint Paul, Phoenix and Los Angeles) $)^{4,9-11}$. We have observed remarkable homogenization of soil variables, whereby parameters ranging from moisture content to soil nitrogen cycling to microbial biomass all vary less among residential sites than among natural reference sites across the continent. Moreover, while we assumed that urban and suburban land-use change and homogenization would markedly decrease carbon sequestration at parcel, landscape, regional and continental scales, effects are much more complex and variable. In arid regions, both soil and vegetation carbon stocks are increased by urbanization due to addition of water and planting of shrubs and trees, while in humid regions, carbon stocks in unpaved soils (the largest reservoir) are either increased or unchanged by urbanization. The net effect of urbanization on carbon sequestration in humid regions depends on just how much aboveground carbon is lost, which varies greatly within and between cities and is amenable to management.

\section{More species but less diversity} Residential landscapes contain turf grass, weeds and numerous exotic and native herbaceous species, and a variety of trees and shrubs. These plant assemblages contribute to the overall managed and emergent diversity of urban landscapes and reflect social and structural drivers (such as aesthetic preferences and norms as well as the availability of certain plant species) of landscaping decisions. Urbanization reduces differences in plant community composition and aboveground biomass among biophysically dissimilar regions because 


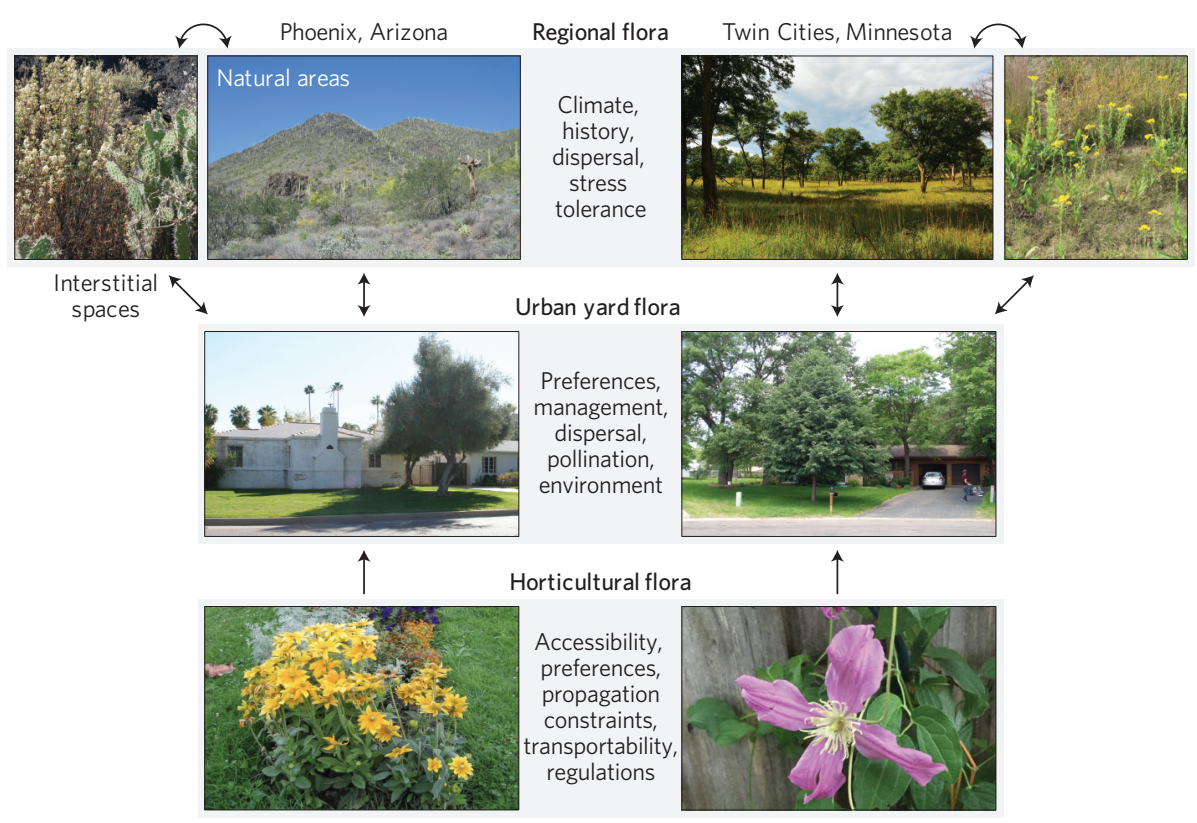

Figure 1 | An example of urban homogenization of yard vegetation between Phoenix and MinneapolisSaint Paul. Flora in urban yards assemble from spontaneous and cultivated species of the regional flora (both native and non-native species, including weeds) and flora provided by the horticulture industry (largely non-native species), subject to different filters (middle column). Despite dissimilar climates that give rise to very different flora in natural areas (desert in Phoenix, oak savannah in Minneapolis-Saint Paul), urban yards in these two cities have similar structure and the spontaneous species in them come from relatively few evolutionary lineages, while the cultivated species come from a diversity of lineages. Species that escape cultivation, and spontaneous species fostered by the urban environment can disperse back to natural areas through interstitial spaces to become a greater component of the regional flora.

residential areas have similar landscaping. Thus, relative to the composition of native ecosystems in these regions, the plant community composition is more similar. When comparing residential lawns and native herbaceous communities, there was strong evidence for homogenization of plant communities in analyses that both included or excluded turf grass species.

Analysis of the flora of entire residential yards and native reference systems showed that the urban flora have lower turnover in species and phylogenetic composition across climatic regions than the native flora ${ }^{12}$. As a result, the urban flora has higher species richness but relatively lower phylogenetic diversity than the flora in natural areas due to the high number of exotic urban species from relatively few phylogenetic lineages.

\section{Impacts beyond residential yards}

The analysis of whole yards leads to new ideas about assembly of vegetation communities in the American residential macrosystem and in the less humandominated systems that are intermixed with, adjacent to, and affected by these communities (Fig. 1). The major sources of urban flora are subject to contrasting filtering processes, each of which varies with spatial scale and likely by geographical region. The horticultural flora is influenced by accessibility of plant material, propagation constraints, and human preferences, and is further filtered by regulation and management processes. In contrast, the continental flora is influenced by historical biogeographic processes and filtered by dispersal limits and climatic and edaphic constraints ${ }^{13,14}$. Similarly, cultivated and spontaneous pools within the regional and urban flora are subject to contrasting dispersal and filtering processes within the urban environment. For example, cultivated species are likely filtered by human preferences and management and often receive additional resources (for example, water, fertilizer, weed control). Spontaneously regenerating species are also likely filtered by human preferences and management (for example, mowing and fertilizing), as well as by dispersal and broader urban environmental conditions.

Cultivated species may 'escape' cultivation to become part of the spontaneous flora of urban and surrounding natural areas and wider regional species pools ${ }^{12,15}$. Natural areas within and surrounding cities are thus likely to be mixed assemblages derived from the interactions between these contrasting species pools. These cultivated landscapes also have implications for bird and insect communities since these animals have strong associations with local plant communities at both the yard and landscape scales ${ }^{16,17}$. Lastly, the filtering processes of managed landscapes may create novel selective pressures that alter organismal phenotypes, change the composition of biodiversity, and give rise to different evolutionary trajectories in managed and unmanaged areas ${ }^{18,19}$. One hypothesis is that the environmental conditions of urban areas select for species that are well adapted to the warmer, more variable climatic conditions predicted to dominate the planet in coming decades. If so, then the diffusion of these species will influence the dynamics of unmanaged areas as these changes occur.

\section{Futures for residential macrosystems}

We have focused on the complex and dynamic human actions at multiple spatial and temporal scales, for example, parcel, neighbourhood and region (metropolitan statistical area) $7,8,20,21$, that influence the development and maintenance of the American residential macrosystem. The dynamism of these actions suggests that the diversity, composition and structure, as well as ecosystem functions and services, of this macrosystem are subject to change over time frames of 50-100 years with potentially significant continentalscale effects on ecological processes and environmental quality.

Future research needs to determine how drivers of change, such as shifts in human population and ethnicity, increasing desire for biodiversity and water conservation, and regulations governing water use and quality, will interact with stabilizing factors, such as social norms, property values, neighbourhood and city covenants and laws, and commercial interests, to produce marked differences in ecological processes in residential macrosystems. For instance, will widespread management that promotes nutrient- and water-use efficient and wildlife-supporting plants as well as lower inputs of water and nutrients give rise to greater regional biodiversity across trophic levels, higher nutrient retention, lower water use, and reduced runoff and losses of soil carbon and nitrogen from residential yards at the regional scale? Or do the constraints imposed on ecological processes by the unique structural attributes of cities (that is, their high degree of imperviousness and their high habitat fragmentation) override the effects of management decisions? There is also a great need to determine how these coupled biophysical and social dynamics vary within and between cities. For example, 
although landscape preferences and decisions may vary across households at the parcel scale, the dominant reasons for yard management - that is, aesthetics, ease-ofmaintenance, and norms of neatness - are largely similar across regions ${ }^{7}$. Yet some within-region and cross-region distinctions exist, such as variation across individual preferences (for example, for neat, orderly lawns versus more naturalistic, non-grass landscapes) as well as across cities in northern, cold regions relative to those in the warm Sun Belt, where cooling vegetation is more of a priority. Understanding the outcomes of residential landscapes "may require a multiscale, differentiated approach because the underlying social practices appear relatively varied"s.

It is important to recognize that while dense urban land use occupies a relatively small area of the Earth's surface, suburban and exurban land use is much more common. More importantly, we suggest that the effects of urbanization on biodiversity, hydrology and biogeochemistry will have impacts on community assembly and ecosystem function well beyond residential parcels and landscapes, affecting water quality and the nature and extent of ecosystem response to global environmental change at regional and continental scales. Urban land-use change is clearly a global challenge of similar intensity and extent to agricultural land-use change and other components of global environmental change.
Finally, a major question is if a distinct socio-ecological theory of urban ecology is needed, or if current theories from biophysical and social domains can be used in combination or in complementary ways to address the research challenges outlined above. We argue that transdisciplinary, multi-scale research in urban ecology presents both theoretical and practical challenges that should be a focal area in ecology and evolution over the next few decades.

Peter M. Groffman is at Advanced Science Research Center at the Graduate Center of the City University of New York, New York, New York 10031, USA. Meghan Avolio is at the National Socio-Environmental Synthesis Center, Annapolis Maryland 21401, USA. Jeannine CavenderBares, Sarah E. Hobbie and Kristen C. Nelson are at University of Minnesota, Saint Paul, Minnesota 55108, USA. Neil D. Bettez is at the Cary Institute of Ecosystem Studies, Millbrook, New York 12545, USA. J. Morgan Grove is at USDA Forest Service, Baltimore, Maryland 21228, USA. Susannah B. Lerman is at USDA Forest Service, USDA Forest Service Northern Research Station Amherst, Massachusetts 01003, USA. Kelli L. Larson and Sharon J. Hall are at Arizona State University, Tempe, Arizona 85281, USA. Dexter H. Locke and Rinku Roy Chowdhury are at Clark University, Worcester, Massachusetts 01610, USA. James B. Heffernan is at Duke University, Durham, North Carolina 27708, USA. Jennifer L. Morse is at Environmental Science and
Management, Portland State University, Portland, Oregon 97201, USA. Christopher Neill is at Woods Hole Research Center, Falmouth, Massachusetts 02540, USA. Jarlath O'Neil-Dunne is at University of Vermont, Burlington, Vermont 05405 USA.

Diane E. Pataki is at University of Utah, Salt Lake City, Utah 84112, USA. Colin Polsky is at Florida Atlantic University, Davie, Florida 33314, USA.

Tara L. E. Trammell is at University of Delaware, Delaware 19716, USA.

e-mail: peter.groffman@asrc.cuny.edu

References

1. Brown, D. G. et al. Ecol. Appl. 15, 1851-1863 (2005).

2. Tanner, C. J. et al. Front. Ecol. Environ. 12, 574-581 (2014).

3. Grimm, N. B. et al. Front. Ecol. Environ. 6, 264-272 (2008).

4. Groffman, P. M. et al. Front. Ecol. Environ. 12, 74-81 (2014).

5. Pouyat, R. V. et al. in Urban Ecosystem Ecology (eds Aitkenhead-Peterson, J. \& Volder, A.) 119-152 (American Society of Agronomy, 2010).

6. Heffernan, J. B. et al. Front. Ecol. Environ. 12, 5-14 (2014).

7. Larson, K. L. et al. Urban Ecosyst. 19, 95-113 (2015).

8. Polsky, C. et al. Proc. Natl Acad. Sci. USA 111, 4432-4437 (2014)

9. Hall, S. et al. Landscape Ecol. 31, 101-117 (2015).

10. Trammell, T. L. E. et al. Oecologia 181, 271-285 (2016).

11. Steele, M. K. et al. Ecosystems 17, 685-697 (2014).

12. Pearse, W. D. et al. Preprint at bioRxiv http://doi.org/b68x (2016).

13. Wiens, J. J. et al. Ecol. Lett. 13, 1310-1324 (2010).

14. Cavender-Bares, J. et al. Annu. Rev. Ecol. Evol. System. 47, 4330462 (2016).

15. Knapp, S. et al. Ecol. Lett. 11, 1054-1064 (2008)

16. Frankie, G. W. et al. J. Kansas Entomol. Soc. 78, 227-246 (2005).

17. Lerman, S. B. \& Warren, P. S. Ecol. Appl. 21, 1327-1339 (2011).

18. Alberti, M. Trends Ecol. Evol. 30, 114-126 (2014).

19. Cheptou, P.-O. et al. Proc. Natl Acad. Sci. USA 105, 3796-3799 (2008).

20. Groffman, P. M. et al. Environ. Res. Lett. 11, 034004 (2016).

21. Epp Schmidt, D. J. et al. Nat. Ecol. Evol. 1, 0123 (2017).

Competing interests

The authors declare no competing financial interests. 